\title{
Data as a driver for shaping the practices of a preventive healthcare service delivery network
}

\author{
Minna A. Pikkarainen \\ minna.pikkarainen@oulu.fi| Martti Ahtisaari Institute, University of Oulu, Oulu Business School, P.O. \\ Box 4600, 90014 University of Oulu, Finland \\ Saara Pekkarinen \\ saara.pekkarinen10@gmail.com | Oulu Business School, University of Oulu \\ Timo Koivumaki \\ timo.koivumaki@oulu.fi|Oulu Business School, University of Oulu \\ Tero T. Huhtala \\ tero.huhtala@oulu.fi|Oulu Business School
}

\begin{abstract}
Though data is largely recognized as a new form of capital in the digital era, little research has been done on how innovations related to finding health professionals and using health services are evolving in smart-city-based, preventive healthcare service delivery networks. How does digital data affect preventive healthcare practices in service delivery networks? Evidence is provided from a smart city service delivery network on how data and ICT usage impact preventive healthcare innovations. The research is based on a case study highlighting the transformations continuously occurring in such a network. The results suggest that using data from different sectors will enable individuals and health professionals to communicate via intelligent personalized services, which will act as agents, guiding and coaching individuals to change their lifestyles to avoid chronic diseases. This study provides new knowledge on how continuously using health data can produce novel routines and innovations in healthcare networks over time.
\end{abstract}

Keywords. Digitalization; Data Driven; Practices; Innovation; Service Delivery Network.

Cite paper as: Pikkarainen, M., Pekkarinen, S., Koivumaki, T., Huhtala, T., (2018). Data as a driver for shaping the practices of a preventive healthcare service delivery network, Journal of Innovation Management, www.open-jim.org, 6(1), 55-79. http://hdl.handle.net/10216/111571 


\section{Introduction}

The paradigm of healthcare is changing dramatically to respond to the challenge of increasing costs and the needs of an ageing population (Karanikolos et al., 2013). There is an ongoing transformation of health solutions - a change in which the interventions aimed at innovation changes are affecting smart city ecosystems, which typically include actors from multiple technology organizations, care providers and individuals (Best et al., 2012). ICT-driven innovations have been continuously developed in the health care sector to cover such basic practices as a) finding the right health professionals and b) knowing how to use existing health facilities.

The health innovations currently being developed are digital or digitally enabled innovations, which are driven by data and involve both physical and digital components for novel market offerings (Lusch \& Nambisan, 2015) (for more on decision support systems, see, e.g., Wimmer et al. 2016). The digital components will help individuals access health care facilities more easily, independent of time and place, and support healthcare organizations in detecting diseases earlier (Raghupathi \& Raghupathi, 2014). Therefore, the role of data is very crucial to such digitalization efforts (Ylijoki \& Porras, 2016).

An increasing number of mobile applications are appearing every year that collect data from individuals in different domains. Already in 2013, almost a hundred thousand mobile apps existed and nearly 500 wearable devices had been released annually. (Sharon, 2016.) Individuals have started to use smartphone applications and wearable mobile sensors that make it possible to monitor, for instance, sleep, food, exercise, and blood sugar. This kind of self-measured data is helping individuals take better and more efficient care of their own health (Sharon, 2016). Nearly everything can nowadays be quantified by means of sensors, sequencing, laboratory tests and scans (Kish and Topol, 2015), and the collected data can be used for self-reflection, supporting individuals' efforts to change own behavior (Carver \& Scheier, 2001). This means that the participatory role of individuals is a vital aspect in reducing healthcare costs (Sharon, 2016). Data is a valuable asset (Xie et al., 2016), and it will become even more valuable when data items from various sources form meaningful chunks of information (Ylijoki \& Porras, 2016, p.7). Successful innovations should group sensing and supporting technologies as well as the needs of individuals around data in a manner that is highly personalized. This will make the individual a driver of his/her own health and wellbeing (McGrath \& Scanaill, 2013).

A service delivery network consists of two or more organizations that are responsible for a connected, overall service (Tax et al., 2013). It is a network in which different players, such as smart city managers, physicians, hospitals and insurance companies, are continuously exploring better ways to understand the impacts of data on their services. They are co-developing and deploying services together with private companies, patients and health experts in order to reduce costs and improve their services (Pramanik et al., 2017.) In preventive healthcare, digital solutions are continuously changing and there are many unaddressed problems related to the digitalization and the changes being caused by it (Solanas et al., 2014).

A smart city is typically a coordinator organization that is responsible for responding intelligently to individual needs in the healthcare sector with respect to the service delivery networks (Pramanik et al., 2016). IBM and Intel, prominent guidance actors in this sector, identify smart health as one of the key fields that will make a smart city (Caragliu, del Bo, \& Nijkamp, 2009). 
The appearance of big data has great potential for innovations supported by the public sector (Roy, 2016) in smart-city-related networks (see, e.g., Moore, 2006; Diamond, 2009).

The network players, that is, healthcare organizations and cities, need to continuously discover and develop healthcare technologies that serve citizens. In the healthcare context, smart cities are often providing infrastructure-supporting data collection measures, processing, storage, transmission and sharing services. Additionally, they are often helping hospitals achieve smart healthcare services. (Pramanik et al., 2016.) Health data can be collected, for example, through the use of medical equipment, supplies and communication systems ( $\mathrm{Su}$ et al., 2011). Thus, the prospects of using big data to facilitate smart cities are promising. From a company perspective, data can be considered like oil; combined with data management and analytics processes, data can provide various benefits for organizations in the service delivery network.

Although data is considered a new form of capital, only few academic studies have explored how data can be transformed from a digital resource into a valuable asset (Xie et al., 2016). Even fewer studies have addressed how to do this in smart-city-related, healthcare service delivery networks (see, e.g., Pramanik et al., 2016).

Furthermore, even though data can be used to provide better health solutions and reduce costs (Al Nuaimi et al., 2015), data as an important resource (or valuable asset) in healthcare decision making has remained a relatively understudied researched area. However, (Kawamoto et al., 2005), (Groves et al., 2013) and (Ferlie \& Shortell, 2001), among others, have explored how data as a resource is changing the nature of innovations in the healthcare sector. Even fewer theoretical studies exist that explore how data as a valuable asset is changing practices in the preventive healthcare sector within the context of the network of private and public actors.

Little is known about the mechanisms underlying value co-creation in business-to-business networks that involve multiple partners (Sarker et al., 2012). It is also unclear how these changes in practices and processes are affecting the co-creation of new technology solutions, for instance platforms, data analytics, medical devices, applications and decision support systems. For situations in which market competition is increasingly being manifested as data competition (Xie et al., 2016), there is a need to better understand how data can be used by healthcare organizations and how data use as a valuable asset with respect to innovation is changing practices in the healthcare domain.

The purpose of this paper is to increase understanding of the impact of digital data (being generated from medical devices and healthcare records, produced by diagnostics tools and combined to facilitate individual self-management and clinical interventions) on preventive healthcare practices in service delivery networks.

The study was conducted in the context of a small Finnish city's healthcare network, one which contains players from both the public and private sector who share the goal of offering digital, personalized, high-quality health solutions to citizens, thereby decreasing overall future costs of public healthcare in Finland. This particular Finnish city is referred to as "Smart city" in the study. We define a service delivery network similarly as (Tax et al., 2013), that is, as a network in which the Smart city plays a central role as a coordinator interacting with other service providers. 


\section{Literature review}

\subsection{Data-driven innovations in smart cities in the preventive healthcare domain}

Digitalization is a megatrend, meaning that digital technologies are constantly being integrated into our everyday life. Digitalization can be seen as an important technological evolution that enables fundamental changes, called datafication. (Ylijoki \& Porras, 2016). Organizations from both the public and private sectors have participated to datafication by collecting personal data and using it as a resource for innovation creation. Typically, governmental organizations collect personal data, such as taxes, place of residence and date of birth. Healthcare organizations maintain a variety of health records, whereas business organizations collect, for instance, customer data, including data on shopping behavior, transactions and receipts. In addition, the use of computers, mobile devices, sensors and access to information via the Internet is continuously generating personal data on human behaviors, habits and thoughts (Li et. al., 2011).

Data is a critical resource in healthcare (Beirão et al., 2017), and it plays an important role in improving the strategies for predicting, preventing and managing undesired health conditions (Collins \& Varmus, 2015; Pinho et al., 2014). It is estimated that the amount of medical data will exceed 25,000 petabytes in the U.S. alone by 2020 (Pramanik, et al., 2017). Mobile technology and big data are new resources that are increasingly available and provide opportunities to personalize services and offer better service quality (Amit \& Han, 2017). Previous studies define the term data and big data in different ways. For instance, Ylijoki and Porras (2016) found 17 different definitions for big data, many of which are related to data usage (see, e.g., Tiefenbacher \& Olbrich, 2015; Baro et al., 2015; Bertolucci, 2013; Demchenko et al., 2014). Many companies identify data as a resource for developing valuable innovations (Ylijoki \& Porras, 2016).

A large portion of big data is personal data, which is essentially information that can be directly or indirectly identified regarding an individual person (European Commission, 2016). Recently, there have been many discussions among industries and governments about the human-centered approach to personal data management (Eichelberg et al., 2005; Gnesi et al., 2014; Papadopoulou et al., 2015). In this approach, the role of the individual is changing from that of a data generator to that of an active data manager, meaning that an individual can manage his/her own personal data and decide if the personal data should be shared with other parties (for his/her own benefit). This new trend towards human-centered data management, or the MyData approach, can be one way to release data from organizational silos, making it an important and reusable resource for creating innovations, which will in turn help individuals to manage their lives (Poikola et al., 2015).

In the healthcare domain, many hospitals have begun using Electronic Medical Record systems to improve the quality and the coherence of the care process through automated guidelines and care pathways that provide data about patients for clinical work and research (McDonald, 1997). The electronic medical health records contain a large amount of data collected from each individual that could be used to improve and personalize the act of care taking (Raghupathi \& Raghupathi, 2014). Also, cities around the world are collecting massive amounts of data that contribute to the production of useful information for citizens (Maglio \& Chie-Hyeon, 2016). New forms of citizen involvement and oversight are essential for governments in order for them to pursue 
and realize the benefits of data (Tydd, 2015). It helps health service providers to enhance the customer experience. It also creates new business opportunities for companies (Ylijoki \& Porras, 2016). Both public and private players can use data to improve the health and wellbeing of citizens through preventive healthcare solutions and new diagnosis and treatment tools. Smart coaching is one way to use data in the preventive healthcare sector. Relevant empirical cases (see, e.g., Jung et al., 2010; Takacs et al., 2014) in this category aim to provide evidence-based coaching or management-based coaching on enhanced understanding of human behaviors and context (Maglio \& Chie-Hyeon, 2016).

However, the proper deployment of data applications requires information and communication technology support, for instance through a data platform (Al Nuaimi et al., 2015), which is an important channel for public and private networks to gain access to data resources and offers new value for individuals (Xie et al., 2016). Data platforms enabled via technology development (Lusch \& Nambisan, 2015) are being used for online transactions, virtual networking, open design and mobile interaction (Xie et al., 2016). Technology innovations such as platforms and applications provide easy access to data. Intelligent processing and data visualizations are important tools to support sustainable behavioral change (McGrath \& Scanaill, 2013). Recently, three technical branches have greatly affected technology development in the area of big data and smart cities: 1) intelligent agents (meaning, an autonomous software entity that interacts with its surroundings) (Clancy, 2006; Wimmer et al., 2016); 2) machine learning (which has been used to analyze heterogeneous health data, especially in the area of medical decision making); and 3) text mining (which helps compile large volumes of textual and numeric data about patients) (Pramanik et al., 2017). Additionally, numerous artificial intelligence systems have been built to collect patient data and help health professionals in their decision making (Zakim, 2016; Wimmer et al., 2016). Thus, medical doctors need information from different sources to establish the right diagnosis and treatment plan. The patient needs to know and understand what the problem is and what can be done to improve the situation (Teutsch, 2003).

Table 1. Summary of the literature analysis

\begin{tabular}{ll}
\hline Theme & Reference \\
\hline Personal data generation \& & (Eichelberg et al,. 2005; Gnesi et al., 2014; \\
management & Papadopoulou et al., 2015) \\
Data platforms & (Al Nuaimi et al., 2015; Lusch \& Nambisan, 2015) \\
Data analytics & (Clancy, 2006; Wimmer et al., 2016; Pramanik et al., \\
& 2017) \\
Personalized services, & (Amit \& Han, 2017; Teutsch, 2003) \\
self-diagnostics \& smart coaching & (Jung et al., 2010; Takacs et al., 2014; Maglio \& \\
Smart coaching & Chie-Hyeon, 2016) \\
& (Zakim, 2016; Wimmer et al., 2016) \\
Clinical interventions &
\end{tabular}




\subsection{Theories of practice}

Theories of practice have their roots in the works of Giddens, Bourdieu, Foucault, Heidegger, Wittgenstein and Marx. Social practice theory is a type of social theory that proposes a vocabulary for thinking in new ways about how to consume and use objects in practice (Shove \& Panzar, 2005). It can be used to describe and better understand the dynamics of innovation, relationships with novel products and emerging practices (Reckwitz, 2002, p. 249). Practices are activities that can be identified as the regular, skillful performance of human bodies. They also include routinized mental and emotional activities. Social practices are a set of routinized body performances that can be identified at the same time as mental activities. For example, according to (Black \& Gallan 2015) playing football is a routinized performance that uses certain knowhow and interpretations of the other players' behaviors. In healthcare context, a routinized practice may consist, for example, of finding a health specialist or using a health service.

Practices are always social, shared, emerging, enduring, changing and disappearing across time and space (Giddens, 1984). This is the result of discourse, that is, the interactions between the actors related to these practices (Warde, 2004). Social practices also interact and sustain each other, such as eating often depends on cooking (Blue et al., 2016) or the use of health service depends on finding the right specialist.

Practices always take place between identifiable actors (Black \& Gallan, 2015), and as such, following Ozanne and Anderson (2010, p.123), "we present a community-based participatory research method that engages consumers and stakeholders in research within their local communities to understand and solve difficult community problems." In the healthcare sector, however, the actors can be healthy individuals (when talking about preventive health services), patients (people who have a diagnosed illness), doctors and other health professionals, or third-party players, for example an insurance company, personal trainers or ICT companies (Black \& Gallan, 2015).

According to (Reckwitz, 2002), football players are not just using a ball, they are affecting the reproduction of the game itself. In the healthcare context, both individuals/patients and third-party members can be seen as actors who reproduce the health services over the time.

Objects of practice and the things used to implement the practice are necessary components of practices. For instance, when playing football we need goals and a ball as basic resources, or things (Reckwitz, 2002). With digitalization, Electronic Medical Record systems, e-health, telehealth and m-health solutions as well as data convergence can all be characterized as new things that are increasingly being used to carry out common practices. Most social practices consist of relationships between different bodies, minds and objects. In fact, an individual's social network, family, friends and co-workers can affect the system of health and wellbeing (Black \& Gallan, 2015).

A social practice contains specific forms of knowledge or the information that generates knowledge. That knowledge offers a way to understand the world. In the context of healthcare, patients are, in many cases, dependent on third-party actors for obtaining the information (Black \& Gallan, 2015). On the other hand, third-party actors, such as health specialists, need information from patients to make the right diagnosis and decisions related to their healthcare (Kaba \& Sooriakumaran, 2007) 
According to (Reckwitz, 2002), social practices are routines that motivate the actors. Structure exists beyond time. A process is an application of structures in action. Social structure means that there is an agreement between actors who believe in the same objective. An agent is at the center of social theories of action consisting of mind and body, which in the social world has traditionally contained those individuals, meaning health professionals, whose decisions affect others. Therefore, it is difficult to conceptualize processes that break up structures.

\section{Methods}

Our research question calls for a holistic approach to the phenomenon under analysis; hence, we adopted a case study approach. The Smart city service delivery network was selected for the case study because it is a city that is ahead of other cities in the smart city agenda in Finland. It is also keen on trying to provide good healthcare services to its citizens and to improve the cost efficiency of the health services by decreasing unnecessary doctor visits and increasing virtual services. The city in question has eight health centers in which the patient data system is utilized to provide a diagnosis, laboratory results and entries related to medications. The sparse and widely spread population puts a strain on the city's health centers. A data-driven platform was created and launched in this city for use by its citizens on the 25th of March 2015 to alleviate this challenge. Although the participating companies work in global markets, the Smart city delivery network is located in Finland. The time boundary for the study was $02 / 2016-06 / 2017$. The case study approach is appropriate because it offers researchers the means to investigate the relationships between the concepts of the phenomenon in the chosen context and not just describe them (Yin, 2014). Ketokivi and Choi (2014, p. 238) have provided a figure showing that if existing theories and literature provide the basis for formulating a research question. They claim that there is no possible a priori theoretical hypotheses can be introduced. There is the potential to contextualize an a priori theory otherwise, more generally, than the empirical context. In that case data would allow for if more general insights into the theory can be provided that would make it possible to elaborate more fully on the case study research.

A case study approach enables researchers to gain an in-depth understanding of a complex issue by scrutinizing the phenomenon using multiple data sources. The case study as an empirical form of inquiry is used to investigate a contemporary phenomenon within its real-life context when the boundaries between phenomenon and context are not clearly evident (Yin, 1984). A case study methodology is often used in different domains (Ozanne \& Anderson, 2010; Yin, 2003). In these areas, case studies are conducted to increase knowledge about individuals, groups and organizations as well as about social phenomena. Case studies offer an approach that does not require maintaining a strict boundary between the studied object and its environment; on the contrary, the key aim is to increase understanding of the interactions between the two.

To allow for various sides of the studied phenomenon to be revealed and understood, the study's issues must be examined through multiple lenses rather than just one (Baxter \& Jack, 2008). Defining the frame of reference of the study makes the context of the case study research clear, and it helps both those conducting the research and those reviewing the results of it (Runeson \& Höst, 2008). 


\subsection{Data Collection}

The data collection process consisted of three semi-focused workshops, several meetings and observations, in which the period for data collection was 18 months. The purpose of the workshops, meetings and ten interviews (including the health care providers, companies and insurance organizations) was to facilitate the service delivery network of the Smart city, discuss the roles of digitalization and a human-centered data management approach, and observe their actions and practices in the domain of preventive healthcare. The participants in the workshops were health directors, health specialists and private companies offering technology solutions for residents of the Smart city. Since the study was conducted from the healthcare provider perspective, data was not collected from end users of the solutions as such. However, many of those participating in the workshops also represented the end-user perspective regarding the solution since they were also users of the public service that the Smart city was offering to its residents (see Table 2).

Table 2. Participants in the workshops

\begin{tabular}{|c|c|c|}
\hline Workshop date & Workshop theme & Workshop participants \\
\hline 15.4 .2015 & $\begin{array}{l}\text { Journey planning for } \\
\text { diabetes case }\end{array}$ & $\begin{array}{l}\text { Service coordinator } \\
\text { Supplier company director } 1 \\
\text { Supplier company director } 2 \\
\text { Project manager, Smart city } \\
\text { Service manager, Smart city } \\
\text { Service designer 1, Smart city } \\
\text { Service designer 2, Smart city } \\
\text { Health manager, Smart city } \\
\text { Nurse, Smart city } \\
\text { End user }\end{array}$ \\
\hline 9.12 .2015 & $\begin{array}{l}\text { Value creation among } \\
\text { service ecosystem actors }\end{array}$ & $\begin{array}{l}\text { Health manager, Smart city } \\
\text { Service manager, Smart city } \\
\text { Two service designers, Smart city } \\
\text { Project manager, Smart city } \\
\text { IT service director, Smart city } \\
\text { Deputy chief physician, Smart city } \\
\text { Telecom company director } \\
\text { Physician, Finnish medical society } \\
\text { Two advisors, Finnish innovation fund }\end{array}$ \\
\hline 9.12 .2015 & $\begin{array}{l}2 \text { meetings with Smart } \\
\text { city medical device } \\
\text { provider }\end{array}$ & $\begin{array}{l}3 \text { managers from a medical device \& data } \\
\text { analytics organization working in the Smart } \\
\text { city service delivery network }\end{array}$ \\
\hline
\end{tabular}




\begin{tabular}{lll}
\hline Workshop date & Workshop theme & Workshop participants \\
\hline 10.2 .2016 & Business models, data & Health manager, Smart city \\
& legislation and regulation & Two service managers, Smart city \\
& & Deputy chief physician, Smart city \\
& Administrative chief physician, Smart city \\
& Project manager, Smart city \\
& IT service director, Smart city \\
& Two advisors, Finnish innovation fund \\
& Telecom company director \\
& & Physician, Finnish medical society \\
Spring/Autumn & Observation & Observations in the 3 Mydata alliance \\
& & meetings in which the private companies \\
& & were present \\
\hline
\end{tabular}

The first workshop was held on the 15th of April 2015. The aim was to increase understanding about the potential of digitalization and a human-centered data management approach in the Smart city service delivery network. Those attending the workshop included actors from both the current and potential future service delivery network: healthcare providers and system providers, platform providers and data collection device providers.

The first workshop was centered on a service journey planning session for an online self-careoriented local portal service that had been built for Smart city residents. The focus of the workshop was on the prevention of diabetes. Within the service journey planning session, participants identified service user personas, that is, the archetypes of users who embody the key characteristics, goals and needs of the target user group, as well as the key service delivery network actors and their roles. Eight months later, five Skype meetings were organized together with researchers and Smart city players. During these recorded meetings, digitalization and human-centered data management was openly discussed.

The second workshop was held on the $9^{\text {th }}$ of December 2016. The workshop focused on value creation among the ecosystem actors. Value network analysis provided a way to understand the dependencies between organizational roles and relationships in the service network (Allee, 2008). From a resource perspective, network actors can combine or exchange need-based and solution-oriented information or create new sources of value.

Four additional Skype meetings were organized after the workshops in order to understand the potential of technologies and data usage in the service delivery network. In these meetings, both current and future scenarios were discussed together with researchers and Smart city directors.

The third workshop was held on the $10^{\text {th }}$ of February 2016. In this workshop, the same group of participants discussed the business models and regulation aspects that were both speeding and hindering changes. The aim of the workshop was to obtain more insights about the role of private companies in the change process. Data was also collected from a firm perspective in a meeting in which the researchers discussed digitalization and a human-centered data management with three managers from an organization providing healthcare devices and data analytics. Additional data used in the analysis included feedback surveys and web pages related to the Smart city 
network. Observations were also conducted in three Mydata alliance meetings, in which some of the network companies continued to present and discuss ideas about their future approach in terms of data management and health service creation. All of the workshops and meetings, excluding the meeting with the company providing medical devices, were recorded in audio format. Extensive notes were produced in the meeting with the company providing medical device. All recorded data was transcribed before the data was analyzed.

\subsection{Data Analysis}

The change in healthcare practices in the Smart city service delivery network was analyzed using key elements from social practice theory. In our study, the practices included 1) finding the right health service and 2) using the health service appropriately. The key constructs used in the analysis were process, agent, things and discourse. The key elements of social practice theory were adapted from (Reckwitz, 2002) and used in our analysis in the following way:

1. Process: The process of finding the right health professionals and using the solutions correctly were analyzed throughout the different phases (structure) and changing routines.

2. Agent (body/mind): Health professionals (nurses, doctors, etc.) gain new specific knowledge/data that affects discourse (i.e., communication between the systems and personnel).

3. Things: All medical devices, applications and data platforms are necessary resources for carrying out the practices used to generate a health solution.

4. Discourse: Traditional communication (e.g., face-to-face communication and telephone calls) and communication via systems, i.e., data exchange and data platforms, need to be analyzed in a city context. External discourse refers to communication external to health experienced at home and at the city health center with respect to best practices. Internal discourse pertains to communication taking place inside the health center among health professionals regarding best practices.

The thematic analysis was completed using comparative content analysis (Bryman \& Bell, 2015), which was done by reading interviews, comparing and interpreting notes and transcripts from the interviews and workshops, and reviewing additional data. The codes were again categorized as codes and sub-codes. When finished, the authors went through all the material once again in order to identify a first set of research questions. The analysis technique used was tabulation (Runeson \& Höst, 2008), where the coded data was arranged in Excel, making it possible to obtain an overview of the data. After conducting the theme analysis, the results were arranged in chronological order using process notations. The data was analyzed using two time dimensions: short-term and long-term evolution of practices.

Context of the study The unit of analysis in our case study was the service delivery network (Fig. 1). In a service delivery network, each service provider interacts with the client, who in turn relies on other providers to contribute complementary portions of the overall service. Typically, in a service delivery network the client requires expertise from several professions regarding health management services. Each player in the network is impacted by the client's 
experience. In addition, the providers must interact with one another to coordinate the overall service. (Tax et al., 2013.)

Because the Smart city is a public player, it must conduct public procurement and select the right tools to support the newly emerging social and health practices. The Smart city can be considered the coordinator of the service delivery network. In our context, the client is the resident that the service is targeting.

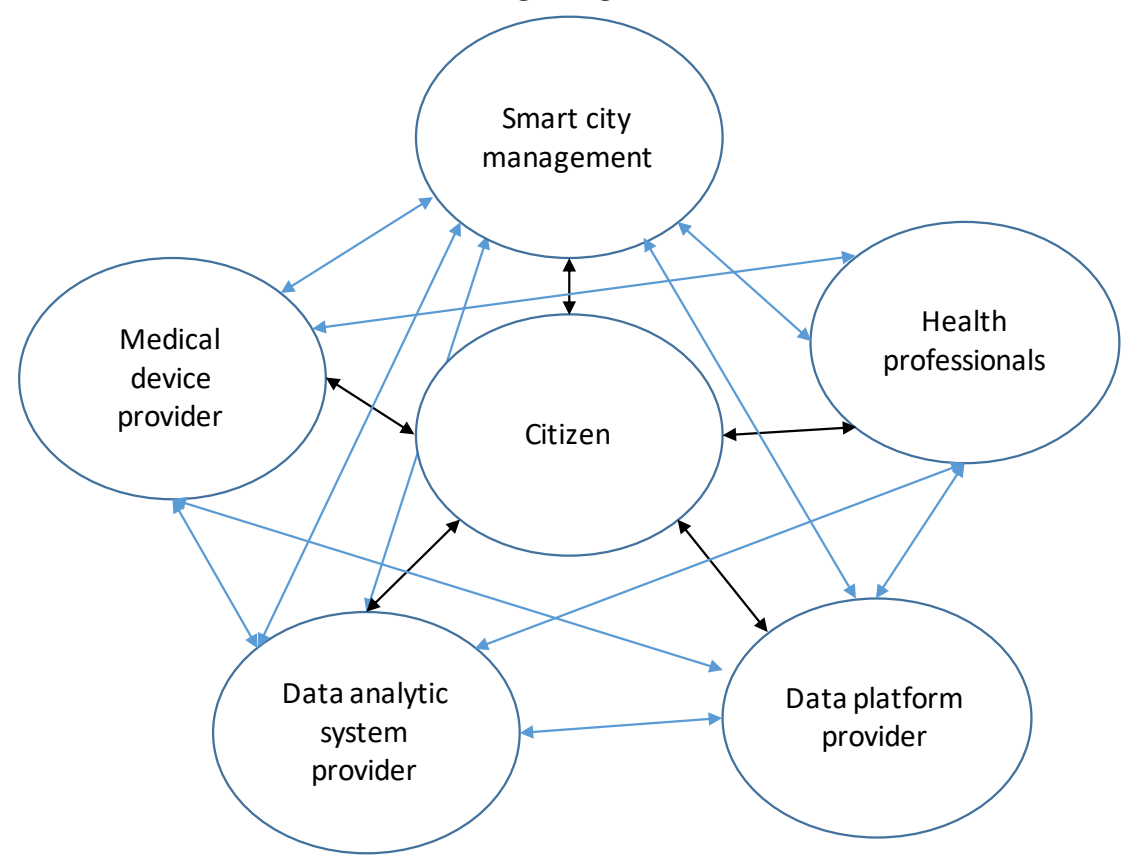

Fig. 1. Smart city service delivery network.

The overall service consisted of several technical components: 1) the data platform, selected from a private organization that had spent ten years developing a platform solution suitable for the purposes of the Smart city, with minor modifications; 2) a data analytics system that was targeted to support health professionals, selected from private player who luckily had a well-validated, nearly completed solution for the Smart city purposes; and, 3) medical devices from one large global company (e.g., peak flow meters and blood pressure meters, blood sugar analysis devices and applications) that allow individuals to measure their condition at home. All of these players were involved in our research workshops and discussions, which were then used as a baseline for data analysis.

\section{Results}

The Smart city had already for a long time emphasized improving the healthcare innovations, the "things," that they were offering to both health professionals and citizens. They were extremely interested in the possibility of using data to improve the care experience of patients as well as the "discursive" communication between systems and actors. The primary goal of the main players 
in the service delivery network was to increase the possibilities for self-monitoring one's health as well as self-diagnostic services. This was done in order to accomplish the following:

empower people either to make some preparations before coming to see the doctor or to take actions to support their own health improvements in such a manner that they would not even need to see the doctor. (Health director from Smart city)

A new type of "discourse" with citizens, private players, made it possible for the Smart city to achieve its goals and to plan new data platforms. It also helped the city to use data analytics to provide its "agents" with advice and recommendations from the healthcare professionals and point out pressing issues regarding personal health as well as offer clients an alternative way to contact healthcare centers. This data changed the routinized practice of agents, causing them to interact with citizen through the platform instead of direct face-to-face communication.

Two user scenarios were identified by the Smart city management and health specialists to investigate the practices in the service delivery network, where several suppliers combine their resources to offer joint service concepts for city residents. In the first case, we investigated the co-creation of data-driven health innovation in the case of diabetes. The diabetes scenario consisted of two supplier companies, a platform provider and diabetes solution provider, doctors and service management. The platform provider in the diabetes case had been operating in the focus market for a long time. The second scenario aimed to build data-driven innovations for the case of chronic obstructive pulmonary disease. In this scenario, we selected two supplier companies (a data collection device provider and a cloud-service and decision-making systems provider), Smart city health service management and doctors as participants. We collected data using a connected PEF meter for asthma status monitoring as well as a cloud service where the data can be transferred from end-user devices.

\section{$4.12015-2016$}

The primary challenge for the Smart city was that it has been receiving an increasing number of health requests from its citizens. These requests could not be solved rapidly enough with the existing resources. Fig. 1 displays the new process and changes that the Smart city generated as part of its routinized practices over time (structure). 


\begin{tabular}{|c|c|c|}
\hline $\begin{array}{l}\text { Data from face to face } \\
\text { discussions \& first home } \\
\text { measurements }\end{array}$ & $\begin{array}{l}\text { Data from health records \& } \\
\text { selected medical devices }\end{array}$ & $\begin{array}{l}\text { Data from different sectors } \\
\text { due to personal data } \\
\text { management approach }\end{array}$ \\
\hline $\begin{array}{l}\text { First home measurements } \\
\text { manually in selected cases } \\
\text { (case of sickness, not } \\
\text { prevention }\end{array}$ & $\begin{array}{l}\text { More home measurements } \\
\text { e.g. in case of astma and } \\
\text { diabetes, data sent } \\
\text { automatically to platform }\end{array}$ & $\begin{array}{l}\text { Continuous home } \\
\text { measurement \& symptom } \\
\text { evaluation guiding individual } \\
\text { to right professional when } \\
\text { needed }\end{array}$ \\
\hline $\begin{array}{l}\text { Face to face meetings with } \\
\text { doctor, role of nurse was } \\
\text { increasing }\end{array}$ & $\begin{array}{l}\text { Symptom evaluation } \\
\text { practice \& guidelines for } \\
\text { individuals to improve life } \\
\text { style; virtual meetings with } \\
\text { nurse / doctors }\end{array}$ & $\begin{array}{l}\text { Continuous, personal } \\
\text { guidelines to improve life } \\
\text { style, personal rewarding, } \\
\text { virtual appointments with } \\
\text { any professionals when } \\
\text { needed }\end{array}$ \\
\hline 2015 & 2016 & 2017- 2025 \\
\hline
\end{tabular}

Fig. 2. Data impact on practices - finding the right health professionals and using the solution.

The first step in improving discourses regarding individual health in 2015 was to create a new symptom evaluation practice in which the individual explains her/his symptoms using a digital platform. The idea behind the new practice was, first, to collect all the available data about a person's eating and exercising habits, blood pressure, and so forth, and second, to use it to provide the relevant information about residents to the proper agents, that is, doctors and nurses. The objective was that the agents would carry out the practice to help the person immediately should the situation get any worse (e.g., blood pressure is routinely abnormally high in in the case of chronic obstructive pulmonary disease).

After responding to the symptom evaluation, an individual would be empowered to use the application either to improve his/her lifestyle or contact a health professional. Previously, the only agent in the system had been health professionals, who had received new specific knowledge/data about a patient and changed their course of action accordingly. With the new practice, individuals took on the role of agent, helping themselves based on the existing discursive guidelines provided to them by the intelligent data analytic system.

An electronic health check was another practice that the Smart city offered to its residents via a new data platform, decision support systems, medical devices and applications. The electronic health check supports people's access to the right types of health professionals. The health check was based on a query in which a person provided personal particulars like age, weight, blood pressure and cholesterol level.

Based on this information, the system gives the person a potential risk evaluation related to any illnesses, such as diabetes, coronary artery disease or dementia, or alternatively, gives [an indication of] how many healthy years the person will most likely have with this particular lifestyle.

In order to achieve the goal of changed practices, the Smart city needed many new innovative tools, "things," for example a platform, analytics, medical devices and applications that helped 
the agents (i.e., health professionals) make remote decisions about an individual diagnosis. These innovations were created based on advice coming from a discourse, a decision-making system, which uses both medical and personal data.

One primary challenge that the Smart city players had noticed already in 2015 was that they had good practices and solutions for sickness management, but insufficient tools and practices for helping citizens prevent future healthcare problems. To support its preventive healthcare target, the Smart city ordered a data platform, decision support system and application "things" that offered individuals a coaching practice based on the existing data. Through the new service, residents can engage in "discourse" with a coaching program and use it to increase their levels of physical activity and manage their eating habits. If the person uses activity trackers, all data can be included in the database in order to give him or her an even better coaching program and guidelines for improving her/his lifestyle.

Through the selected platform, the decision support system, medical devices and application, the Smart city offered to its residents three different options for evaluating their symptoms. For example:

The system asks if the person wants to see a doctor or if he/she just needs medical advice for a health challenge. If the answer is medical advice, the system gives her/him guidelines for how to improve her/his health situation. If the analysis is positive, the person can pick up medicine from the nearest pharmacy within a few hours of the query using an electronic receipt.

Data is collected from both professionals and individuals. With this system, the data from different sources (e.g., laboratories, blood sugar measurements and different diagnoses) are integrated and sent to the decision-making system, which analyzes the data and returns it to the individuals.

The city management realized that they could not capture the full benefits of the collected data before each individual has established her/his own data account, in which the collected data from different sources, such as self-measurements, medical checks (e.g., laboratory results), bank details and location information, can be stored. Luckily, in Finland the intention has been to solve this problem by building a national database (Kanta and Omakanta), which can be seen as an individual's data storage facility for personal medical and self-measured data (http://www.kanta.fi/en/web/ammattilaisille). It allows for the centralized electronic archiving of patient records and long-term storage of the data from different hospitals. The Kanta and Omakanta database plays a central role in the exchange of information between healthcare service providers. Individuals in Finland can see the data recorded by the healthcare units in the OmaKanta service (http://www.kanta.fi/en/web/ammattilaisille/earkiston-esittely). Unfortunately, the Smart city planners found the movement towards the OmaKanta and Kanta database to be too slow; they were ahead of others in their healthcare practices and solution offerings. 


\subsection{Scenario $2017-2025$}

When we were asking about the future practices, the experts from the Smart city network estimated that at some point, there would start to be so much variety in the data collected from each individual that no person would be able to manage it all by themselves. In the future, each person will most likely adopt the practice of using the collected data with intelligent coaching applications, which will help them to continuously check her/his health status, working as an "agent" to improve her/his lifestyle.

Likewise, in the future the health check can be done anytime and anywhere with intelligent analytics and a decision-making system based on the information that the person requests, which will have been shared through a platform operator from his health profile/account. The experts predicted that the increased amount of data coming from different sectors will lead to new opportunities for more accurate, personalized guidelines and diagnoses for the Smart city and those providing its tools:

For example, if the person smokes, he/she will receive some rules and an action plan for how to quit; or, if she/he is overweight, she/he will receive daily guidelines for how to do more sports or how to eat more healthily. If he/she has breathing problems, he/she can receive guidance on how to start using a BEF meter to monitor his/her breathing situation.

If the breathing problems increase, the person may receive an automatic invitation for a digital appointment with a doctor. If the coaching solution is linked with data coming from different sectors, then the person can receive automatic notifications and virtual appointment suggestions from the system for cases in which he/she needs to either see a doctor or some other professional or receive virtual coaching support for his/her personal situation. In this case, the decision support system would begin to act quite intelligently due to the large amount of data that it would seemingly have a "mind" of its own, in addition to a "body," so that we can start to redefine it almost as an "agent" who is proposing actions to support the overall healthcare system based on real-time data.

According to practice theory, every practice implies some intentions - wanting some things and avoiding others. In this case, the Smart city players had conducted a survey asking individuals what they wanted in a healthcare service delivery network. According to their study, individuals want different things: some want face-to-face doctor appointments, while others are happy with a digitally aided solution that would help them avoid unnecessary doctor visits.

According to one expert in the Smart city:

The use of data will radically change the "discursive" doctor's appointments from a social activity to digital coaching. More often, the nurse contacts the person and the doctor is met more often as a virtual activity.

From the object/things perspective, this will increase the need for new digital communication tools, applications and medical devices, all of which can support the development of different types of personalized services that will offer an overall digital solution to individuals' health problems.

Since every practice implies particular intentions, including wanting certain things, it is important 
to find practices and new ways to use data to create new systems and motivate individuals to live a more healthy life. There may also be a need to use personal data from different sectors in order to find different, more personal ways to reward people for improvements in their lifestyle.

In the personal data-based health care system, it will be possible to use data to create rewarding services to identify what a person is interested in. Therefore, it will be possible to provide rewarding lifestyle improvements based on what the person has himself/herself said.

For instance, if a person is interested in taking a holiday trip, he/she could obtain a discount on the price of the trip if he/she has achieved the yearly activity targets. Use of a personal data approach could also enable new types of collective rewarding mechanisms. Fourteen experts in the Smart city mentioned that perhaps in the future, new players, for instance insurance companies, could start to use the data with the permission of individuals to give out rewards for positive actions, such as discounts on insurance payments.

It would be the best way to save costs, if we could really affect the way that a person lives. If many individuals would do more for their own health, there would be far fewer people in the future asking the public healthcare service for help.

Experts in the Smart city also mentioned that the data analytic tools and services would offer additional value to individuals in order to motivate them to share their data with health professionals or personal coaches.

In the future, the insurance companies and private hospitals will most likely start to give discounts to people who are monitoring their health status, using data analytics and improving their lifestyle, showing concrete results by doing so.

\subsection{Summary}

The key result of this study is an increased understanding of the change that is occurring in the preventive healthcare sector due to the use of data as a valuable asset. The main findings discussed throughout this article are summarized in Table 3.

Table 3. Key Findings of the study

\begin{tabular}{ll}
\hline $\begin{array}{l}\text { Practice theory } \\
\text { concept }\end{array}$ & Key Findings \\
\hline Process/Practice: & $\begin{array}{l}\text { The selections made in the technology structure also resulted } \\
\text { in dramatic changes in the routinized practices/actions of } \\
\text { individuals and health professionals. }\end{array}$ \\
Agent (body/mind): & $\begin{array}{l}\text { It was predicted that in a future scenario, the intelligent } \\
\text { decision-making system innovation might be like an agent } \\
\text { having a "body" and "mind," one who also takes an active } \\
\text { role in analyzing the data and guiding people to see the right } \\
\text { professionals in a virtual setting. }\end{array}$
\end{tabular}




\begin{tabular}{ll}
\hline $\begin{array}{l}\text { Practice theory } \\
\text { concept }\end{array}$ & Key Findings \\
\hline Things: & $\begin{array}{l}\text { Smart city ecosystem managers realized that many things are } \\
\text { needed in order to use the data: a platform, intelligent } \\
\text { decision support system, medical devices and applications. } \\
\text { Use of the tools also affects the way that the practices are } \\
\text { evolving. It was also revealed that things will have an even } \\
\text { more important role in the future health care system due to } \\
\text { data usage. } \\
\text { Ways of communicating are changing from face-to-face, social } \\
\text { forms of communication to more digitally aided guidelines } \\
\text { that target behavioral changes and are either received by the } \\
\text { system or through digital communication with professionals } \\
\text { that are selected for the particular person based on the data. }\end{array}$ \\
&
\end{tabular}

\section{Discussion}

From a practice theory perspective, our study supports the argument made by (Reckwitz, 2002) that the actors (individuals and health professionals) actually affect and produce novel, routinized practices in the health sector over time. Typically, new practices emerge if there are people who are able to enact them and who are willing to keep them alive (Blue et al., 2016). Our study demonstrates that the changes in, and emergence of new, practices is also dependent upon smart city players' capability to select and deploy innovations, such as platforms, applications and medical devices.

Our study also shows that in this transformation, the roles of actors are undergoing changes as well. For instance, in the future individuals will have more responsibility to perform selfmeasurements, practice self-data management and make improvements in their own lifestyles or health conditions than before. By doing so, they will communicate more with things/agents (medical devices, applications and platforms) instead of having direct human contact. This finding is in line with that of (Maglio \& Chie-Hyeon, 2016), who also remind us that in the future, it is likely that data analytics can contribute to the automation of information actions, meaning that systems will act on their own to provide support for people. Other authors have also recognized that medical professionals can no longer be expected to be the only source of knowledge regarding an individual's own wellbeing (Frow et al. 2016; Ostrom et al., 2015).

One interesting question for future research raised in our analysis is as follows: What will be the role of data platforms, intelligent decision-making systems and medical devices in future service delivery networks? Moreover, will companies be creating symptom evaluation and coaching systems intelligent enough that they almost appear to have a "mind" and "body" of their own, capable of acting as new agents who will monitor and steer the health of individuals more often and in a more reliable manner than medical doctors or nurses?

This research supports the claim made by (Shove \& Pantzar, 2005) that individuals and orga- 
nizations are both involved in creating new practices. Like the Smart city, other cities should also strongly endorse the use of data and improve novel digital, human-centered solutions and personal data management to support the empowerment of individuals, decrease the cost of healthcare and increase business opportunities for organizations. One bottleneck in current data sharing results from the fact that individuals fear that their personal data will end up in the wrong hands and will be used against them in some future situation (Harjumaa et al., 2016). (Poikola et al., 2015) claim that the human-centered data management approach will need to provide transparency mechanisms that openly show how organizations will use the data and, in doing so, bring value to the individuals.

This study reinforces the belief of (Porter \& Lee, 2013) that the processes and technology solutions employed in the healthcare domain are currently undergoing dramatic changes, in which individuals are expected to move from passive receivers to active contributors. They (individuals) will play an ever more active and varying role in the preventive healthcare system, controlling their own data by becoming agents in the system. On the other hand, doctors are expected to use data-driven decision making systems and virtual communication to make appropriate diagnoses of the case independent of time and place.

Data on the daily life, medical status and risk factors of individuals has often been collected and stored separately in different places. Integrating that data so that it can be used in health care will provide possibilities for personalizing healthcare based on different types of data and data analytics. However, the most successful health innovations will use data from different sources regarding the needs of individuals in a manner that is highly personalized and supportive, and it will continue to evolve with the individuals according to their needs (McGrath \& Scanaill, 2013). Data can be seen as an enabler for the emerging, more personalized health solutions. These solutions include technology enabled e-health, telehealth or m-health services that provide easy access to data from different sources with intelligent ways of processing and presenting the data (Kvedar et al., 2014).

Our study has implications for policy level innovation management. It supports the argument of (Kwon et al., 2015) that the role of smart city policy makers as network coordinators is not only necessary for innovation, but can also lead to changes in the business operations occurring in their particular area of expertise. The way that things, for instance data collection devices, platforms and analytic tools, are invented and used is also changing the practices taking place in the city network, and vice versa.

\subsection{Limitations}

Our study has the following limitations. First, it is a single case study of a service delivery network, which affects the generalizability of the conclusions. Yet, there are good reasons for selecting such an approach. Focusing on a single case means that the study could be done with great subtlety compared to a study of multiple cases. According to (Yin, 2014), such a study may act as a prelude to further studies on a relatively new topic, in this case digitalization. The second limitation concerns the completeness of the study. Only a subset of the participants acting as smart city players participated in the workshops and meetings. We did, however, carefully select the subset of people and their roles in the process together with the appropriate Smart 
city representative, including representatives from each identified player in the Smart city service delivery network. The third limitation concerns the amount of data used for the analysis. Each of the three-hour workshops and several meetings was carefully structured and prepared. Thus, they resulted in a large amount of recorded and transcribed research material from an extended period of time.

As with any theoretical approach, practice theories have their strengths and limitations. Although practice theories allow us to understand the problematic dichotomies existing between individuals and social structures, rational actions and habits, it offers quite complex guidelines for intervention (Blue et al., 2016). Our study is in line with the findings presented by (Blue et al., 2016), who argue that practice theories can be used to support the design and implementation of strategies and policies aimed at improving public health (Blue et al., 2016). In fact, our study shows that social theories of practice are useful for making sense of the changes that are occurring in the health practices, in part due to the new innovations that are radically changing the behavior of both individuals and professionals in public health contexts.

Although our study is about the service delivery network, it assessed how practices are generated more from the perspective of the other network players than from the end user (i.e., customer) perspective. The Smart city network players continuously tried to rethink and create the services from a customer perspective. However, it would be interesting to take a closer look at how customers are actually involved in the service creation process for the Smart city service delivery network and how their role and feedback actually impacts the evolution of healthcare practices and tools. The existing literature has failed to evaluate the impacts of co-creation in the networks in which the software vendors are working with their client organizations (e.g., smart cities) to co-create value for end users (Sarker et al., 2012). In this study, we evaluated the implications of the value co-creation networks established between the Smart city and its vendors, focusing our analysis on best practices and how new tools are developed. In the future, it would be interesting to also evaluate the impacts from the end user and cost perspectives. In fact, longitudinal research would be needed to show how successful the Smart city network actually has been in terms of meeting its targets of introducing benefits to customers by improving the end user experience and overall efficiency of the health care service.

\subsection{Conclusions}

Over time, the Smart city network adopted digitalized solutions and began to exchange and disseminate ideas within and between the public, private players and individuals. From its origins, the use of data has and will transform the practice of locating the right healthcare professional and using the appropriate health solution. After engaging with the new process, the Smart city network players have managed to empower individuals to change their own lifestyles. With these changes, the Smart city created more time for doctors to focus on those patients that, according to the data, really need and want their help. The change has required the Smart city to make new investments and engage in co-creation efforts with different players in the private sector in order to co-create new "things": platforms, data analytics, an intelligent decision support system, medical devices and applications. The co-creation of these new things has radically changed the routinized actions of different actors in the service delivery network. Moreover, the 
discursive communication between the actors has changed from face-to-face discussions to mobile phone advice. In this context, the role of intelligent decision support systems and applications will change from things to agents, who have a body and a mind, and active players in the system helping individuals in how to use the data. A personal data management approach in which individuals can control their own data seems to be the way to release data from different sectors so that it can be used by networks like a smart city to support individuals.

Acknowledgements The authors would like to thank Tekes (The Finnish Funding Agency) and the Digital Health Revolution project for supporting the study as well as personnel from the Smart city for participating in the study.

\section{References}

Allee, V. (2008). Reconfiguring the value network. Journal of Business Strategy, 21(4), July-Aug. Al Nuaimi, E., Al Neyadi, J., Mohamed, N., \& Al-Jaroodi, J. (2015). Applications of big data to smart cities. Journal of Internet Services and Applications, 6, 25.

Amit, R., \& Han, X., (2017). Value creation through novel resource configurations in a digitally enabled world. Strategic Entrepreneurship Journal, 11(3), 228-242.

Beirão, G., Patrício, L., \& Fisk, R. P. (2017). Value cocreation in service ecosystems: Investigating health care at the micro, meso, and macro levels. Journal of Service Management, 28(2), $227-249$.

Baxter, P., \& Jack, S. (2008). Qualitative Case Study Methodology: Study Design and Implementation for Novice Researchers. The Qualitative Report, 13(4), 544-559.

url: http://nsuworks.nova.edu/tqr/vol13/iss4/2.

Baro, E., Degoul, S., Beuscart, R., \& Chazard, E. (2015). Toward a Literature-Driven Definition of Big Data in Healthcare. BioMed Research International, 1-9.

Bertolucci, J. (2013). Big Data: A Practical Definition. Informationweek - Online.

Best, A., Greenhalgh, T, Lewis, S., Saul, J.E., Carroll, S., \& Bitz, J. (2012). Large-system transformation in health care: A realist review. Milbank Quarterly, 90(3), 421-456.

Black, H.G., \& Gallan, A.S. (2015). Transformative service networks: Cocreated value as wellbeing. The Service Industries Journal, 35(15-16), 826-845.

url: http://dx.doi.org/10.1080/02642069.2015.1090978.

Blue, S. Shove, E. Carmona, C. \&Kelly, M.P. (2014) Theories of practice and public health: understanding (un)healthy practices, Critical Public Health, 26:1, 36-50, DOI: 10.1080/09581596.2014.980396

Bryman, A., \& Bell, E. (2015). Business Research Methods (4 ${ }^{\text {th }}$ ed.). Oxford, UK: Oxford University Press.

Caragliu, A., del Bo, C., \& Nijkamp, P. (2009). Smart cities in Europe. In Proceedings of $3^{\text {rd }}$ central European conference on regional science. CERS'09 (pp. 45-59).

Carver, D., \& Scheier, M. (2001). On the self-regulation of behavior. Cambridge, UK: Cambridge 
University Press.

Clancy, C.M. (2006). Getting to smart health care. Health affairs, 25(6), 589-592.

Collins, F. S., \& Varmus, H. (2015). A New Initiative on Precision Medicine. The NEW ENGLAND JOURNAL of MEDICINE, 26(9).

Demchenko, Y., DeLaat, C., Membrey, P. (2014). Defining architecture components of the Big Data Ecosystem. Collaboration Technologies and Systems (CTS), 2014 International Conference on 104-112.

Diamond, C.C., Mostashari, F., \& Shirky, C. (2009). Collecting and sharing data for population health: a new paradigm. Health Affairs, 28(2), 454-466.

Eichelberg, M., Aden, T., Riesmeier, J., Dogac, A., \& Laleci, G.B. (2005). A survey and analysis of electronic healthcare record standards. ACM Computing Surveys, 37(4), 277-315.

European commission, 2016. The EU Data Protection Reform and Big Data Factsheet 2016. [Online] Available at:

url: http://ec.europa.eu/justice/data-protection/files/data-protection-big-data_factsheet_web_en.pdf

Ferlie, E.B., \& Shortell, S.M. (2001). Improving the quality of health care in the United Kingdom and the United States: a framework for change. The Milbank Quarterly 79(2), 281-315.

Frow, P., McColl-Kennedy, J. R., \& Payne, A. (2016). Co-creation practices: Their role in shaping a health care ecosystem. Industrial Marketing Management, 56, 24-39.

Giddens, A. (1984). The constitution of society: Outline of the theory of structuration. Berkley: University of California Press.

Gnesi, S., Matteucci, I., Moiso, C., Mori, P., Petrocchi, M., \& Vescovi, M. (2014). My Data, Your Data, Our Data: Managing Privacy Preferences in Multiple Subjects Personal Data. Lecture Notes in Computer Science, 8450, 154-171.

Groves, P., Kayyali, B., Knott, D., \& Van Kuiken, S. (2013). The 'big data'revolution in healthcare. McKinsey Quarterly, 2, 3.

Harjumaa, M., Saraniemi, S., Pekkarinen, S., Lappi, M., Similä, H., \& Isomursu, M. (2016). Feasibility of digital footprint data for health analytics and services: an explorative pilot study. BMC Medical Informatics and Decision Making, 16(139), 1-9. DOI10.1186/s12911-016-0378-0.

Jung, J., Park, H., Kang, S., Lee, S., \& Hahn, M. (2010). Measurement of initial motion of a flying golf ball with multi-exposure images for screen-golf. Consumer Electronics, IEEE Transactions on, 56(2), 516-523.

Kaba, R., \& Sooriakumaran, P. (2007). The evolution of the doctor-patient relationship. International Journal of Surgery, 5, 57-65.

Karanikolos, M., Mladovsky, P., Cylus, J., Thomson, S., Basu, S., Stuckler, D., Mackenbach, J.P., \& McKee, M. (2013). Financial crisis, austerity, and health in Europe. Lancet, 381(9874):13231331. doi: 10.1016/S0140-6736(13)60102-6. Epub 2013 Mar 27. PMID:23541059.

Kawamoto, K., Houlihan, C.A., Balas, E.A., \& Lobach, D.F. (2005). Improving clinical practice using clinical decision support systems: a systematic review of trials to identify features critical 
to success. BMJ 330, 765. https://doi.org/10.1136/bmj.38398.500764.8F

Ketokivi, M., \& Choi, T. (2014). Renaissance of case research as a scientific method. Journal of Operation Management, 32, 232-240.

Kish, L.J., \& Topol, R.J. (2015). Unpatients - why patients should own their medical data. Nature Biotechnology, 33, 921-924

Kvedar, J., Coye, M.J., \& Everett, W. (2014). Connected health: a review of technologies and strategies to improve patient care with telemedicine and telehealth. Health Aff (Millwood), 33(2), 194-99. doi: 10.1377/hlthaff.2013.0992.

Kwon, T.H., Kwak, J.H., \& Kim, K. (2015). A Study on the establishment of policies for the activation of a big data industry and prioritization of policies: lessons from Korea, Technology Forecast Society Change, 96, 144-152.

Li, I., Dey, A.K., and Forlizzi, J. 2011. Understanding my data, myself: supporting self-reflection with ubicomp technologies. In Proceedings of the 13th international conference on Ubiquitous computing (UbiComp '11). ACM, New York, NY, USA, 405-414.

Lusch, R.R., \& Nambisan, S. (2015). Service innovation: A service-dominant logic perspective. MIS Quarterly, Special Issue: Service Innovation in the digital age, 39(1), 155-175.

Maglio P., \& Chie-Hyeon L. (2016). Innovation and Big Data in Smart Service Systems, Journal of Innovation Management, 4(1). http://hdl.handle.net/10216/83250 ISSN 2183-0606.

Marcos-Cuevas, J., Nätti, S., Palo, T., \& Baumann, J. (2016). Value co-creation practices and capabilities: Sustained purposeful engagement across B2B systems. Industrial Marketing Management, 56, 97-107.

McDonald, C.J. (1997). The Barriers to Electronic Medical Record Systems and How to Overcome Them. Journal of the American Medical Informatics Association, 4(3), 213-221.

McGrath, M., \& Scanaill, C. (2013). Sensor Technologies, Healthcare, Wellness and Environmental Applications. Apress.

Moore, J. (2006). Uses of managed health care data. U.S. Patent Application No. 11/557, 271.

Moreno, A., \& Carbay, M. (2003). Software agents in health care. Artificial Intelligence in Medicine, 27(3), 229-232.

Ostrom, A.L., Parasuraman, A., Bowen, D.E., Patricio, L., \& Voss, C.A. (2015). Service research priorities in a rapidly changing context. Journal of Service Research, 18(2), 127-159.

Ozanne, J. L., \& Anderson, L. (2010). Community action research, Journal of Public Policy \& Marketing, 29(1), 123-137.

Papadopoulou, E., Stobart, A., Taylor N.K, \& Williams, M.H. (2015). Enabling data subjects to remain data owners. Smart Innovation, Systems and Technologies, 38, 239-248.

Pinho, N., Beirão, G., \& Patrício, L. (2014). Understanding value co-creation in complex services with many actors. Journal of Service Management, 25(4), 470-493.

Poikola, A., Kuikkaniemi, K., \& Honko, H. (2015). MyData - A Nordic Model for human-centered 
personal data management and processing. Ministry of Transport and Communication, OKF, https://creativecommons.org/licenses/sa/4.0/

Porter, M. E., \& Lee, T. H. (2013). The strategy that will fix health care. Harvard Business Review, 91(10), 50-70.

Pramanik, Md.I., Lau, R.Y., Demirkan, H., \& Azad, Md. A.K. ( 2017). Smart health: Big data enabled health paradigm within smart cities. Expert Systems With Applications, 87, 370-383.

Raghupathi, W., \& Raghupathi, V. (2014). Big data analytics in healthcare: promise and potential. Health information science and systems 2(1), 3.

Reckwitz, A. (2002). Toward a theory of social practices: A development in culturalist theorizing. European Journal of Social Theory, 5(2), 243-263.

Roy, R. (2016). Data, Dialogue, and Innovation: Opportunities and Challenges for "Open Government" in Canada. Journal of Innovation Management, 4(1), 22-38, http://hdl.handle. net/10216/83250 ISSN 2183-0606.

Runeson, P., \& Höst, M. (2008). Guidelines for conducting and reporting case study research in software engineering. Empirical Software Engineering, DOI 10.1007/s10664-008-9102-8. Publ. online 19 Dec 2008.

Sarker, S., Sarker, S., Sahaym, A., and Bjorn-Andersen, N. (2012) Exploring Value Cocreation in Relationships Between an ERP Vendor and its Partners: A Revelatory Case Study1, MIS Quarterly, 36(1), 317-338.

Sharon, T. (2016). Self-Tracking for health and the Qualified Self: Re-articulating autonomy, solidarity, and authenticity in an age of personalized healthcare. Philosophy Technologies: DOI 10.1007/sl3347-016-0215-5, 29.

Shove, E., \& Pantzar, M. (2005). Consumers, producers and practices understanding the invention and reinvention of Nordic walking. Journal of Consumer Culture, 5(1), 43-64. doi: $10.1177 / 1469540505049846$.

Solanas, A., Patsakis, C., Conti, M., Vlachos, I. S., Ramos, V., Falcone, F., ... \& MartinezBalleste, A. (2014). Smart health: a context-aware health paradigm within smart cities. IEEE Communications Magazine, 52(8), 74-81.

$\mathrm{Su}, \mathrm{K} ., \mathrm{Li}, \mathrm{J} .$, \& Fu, H. (2011) Smart city and the applications. In proceedings of international conference on electronics, communications and control, pp. 1028-1031, IEEE.

Takacs, J., Pollock, C. L., Guenther, J. R., Bahar, M., Napier, C. \& Hunt, M. A. (2014). Validation of the Fitbit One activity monitor device during treadmill walking. Journal of Science and Medicine in Sport, 17(5), 496-500.

Tax, S. S., McCutcheon, D. \& Wilkinson, I. F., 2013. The Service Delivery Network (SDN): A customer-centric perspective of the customer journey. Journal of Service Research, 16(4), pp. 454-470.

Teutsch C. (2003). Patient-doctor communication. Medical Clinics of North America, 87(5), $1115-1145$. 
Tiefenbacher, K., \& Olbrich, S. (2015). Increasing the Value of Big Data Projects- Investigation of Industrial Success Stories. System Sciences (HICSS), 2015 48th Hawaii International Conference on 294-303.

Tydd, E. (2015). Around the world with open government. Public Administration Today, 42, $52-54$

Warde, A. (2004). Theories of Practice as an approach to consumption. Cultures of Consumption. Working Paper Series, Working Paper No:6, pgs 10., Date: 18 March 2004.

url: http//www.consume.bbk.ac.uk

Xie, K., Wua, Y., \& Xiaoa, J. (2016). Qing Hub Value co-creation between firms and customers: The role of big data-based cooperative assets, Information \& Management 53, 1034-1048.

Zakim, D. (2016). Development and significance of automated history-taking software for clinical medicine, clinical research and basic medical science. Journal Internal Medicine, 280(3), 287299. doi:10.1111/joim.12509.

Ylijoki, O., \& Porras, J. (2016). Perspectives to Definition of Big Data: A Mapping Study and Discussion. Journal of Innovation Management, 4 (1), 69-91. http://hdl.handle.net/10216/83250 ISSN 2183-0606

Yin, R.K. (1984). Case study research design and methods. Michigan: Sage Publications.

Yin, R.K. (2003). Case study research: design and methods (3rd ed.). Thousand Oaks, CA: Sage Publications.

Yin, R.K. (2014). Case study research design and methods (5th ed.). Thousand Oaks, CA: Sage Publishing.

Wimmer, H., Yoon, V.Y., \& Sugimaran, V. (2016). A Multi agent system to support evidence based medicine and clinical decision making via data sharing and privacy. Decision Support Systems, 88, 51-66. 


\section{Biographies}
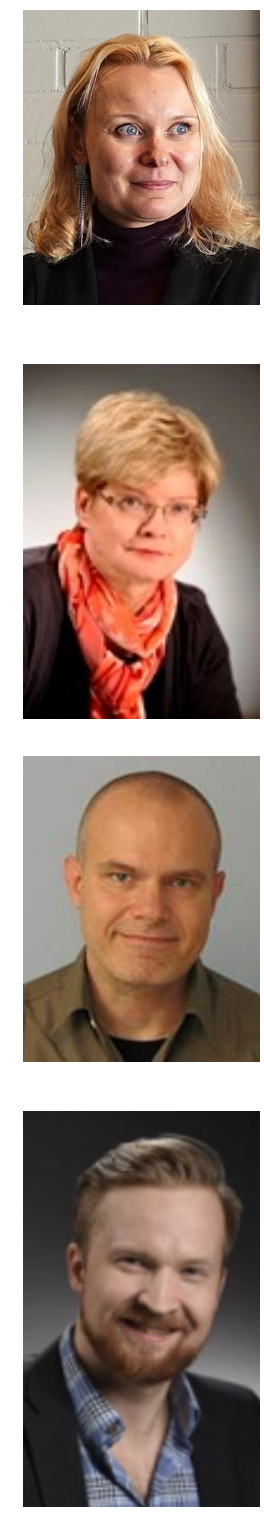

Minna A. Pikkarainen. Minna Pikkarainen, is a joint Connected Health professor of VTT Technical Research Centre of Finland and University of Oulu / Oulu Business School, Martti Ahtisaari Institute and Faculty of Medicine. As a professor of connected health Minna is doing on multidisciplinary research on innovation management, services and business models in the context of connected health. Professor Pikkarainen has extensive record of external funding, her research has been published large amount of journal and conference papers e.g. in the field of innovation management, software engineering and information systems.

Saara Pekkarinen. My main research interest lie upon customer-oriented business relationships, health and wellness service business from modularity and value co-creation perspectives. We have published e.g. Journal of Medical Internet Research, BMC Medical Informatics and Decision Making, Industrial Marketing Management, IJLM, IJPDLM, JBIM, IJSOM and IJLRA.

Timo Koivumaki. Dr. Timo Koivumaki is a professor of digital service business at Martti Ahtisaari Institute, University of Oulu Business School. Previously he has worked as a research professor of mobile business applications at VTT and at University of Oulu, as a professor of information and communication business and as a research professor of electronic commerce at the University of Oulu. All in all, Koivumaki has over 20 years of experience in the field of digital business. His research interests include consumer behavior in digital environments, user-driven innovation, digital service business, digital marketing and strategic networking.

Tero T. Huhtala. Tero Huhtala is a doctoral student at Oulu Business School. His research interests lie in the application of novel digital solutions and new technologies in business. Currently he is finalizing his dissertation on using personal data to advance human-centric services. 